\title{
Influence of Alloying Elements on the Thixoformability of a Chromium Steel
}

\author{
C. Fraipont ${ }^{1}$, J. Lecomte-Beckers ${ }^{2}$ \\ ${ }^{1,2}$ University of Liège, Aerospace \& Mechanical Engineering Department - Chemin des chevreuils, 1 / B52; \\ 4000 Liège; Belgium \\ URL: www.ulg.ac.be/metaux \\ e-mail: Celine.Fraipont@ulg.ac.be; \\ Jacqueline.Lecomte@ulg.ac.be
}

ABSTRACT: This paper deals with the examination of the influence of alloying elements on the thixoformability of a chromium steel. It focuses on the liquid fraction curves of various chromium steels with and without modification of composition. The liquid fraction versus temperature has been obtained by MTData, a thermodynamic prediction package, and by Differential Thermal Analysis (DTA), limited to low heating rates. The correlation between liquid fraction and temperature has been studied. The effect of modifications of composition and of heating rate was observed. First, the thermodynamical calculations allow the study of the influence of alloying elements with variations in chemical composition. Secondly, the DTA tests offer the possibility to observe the influence of heating rate on liquid fraction curve parameters. All these results lead to the identification of the initial parameters necessary to perform inductive heating and quenching tests, and so to approach the industrial process.

Key words: Differential Thermal Analysis (DTA), MTData, thermodynamical study, Thixoforming

\section{INTRODUCTION}

Thixoforming is the shaping of metal components in the semi-solid state. To achieve this, the metal has to fulfill some criteria regarding liquid curve parameters: a weak slope, a low solidus temperature, a large melting interval... For the forming, the microstructure has to consist of solid metal spheroids in a liquid matrix. This microstructure characterizes the thixotropic state. That state leads to a decrease of the viscosity when the material is submitted to shear stresses. It is thus essential to characterize the microstructure and the solidusliquidus interval of alloys to know their thixoformability. The curve of liquid fraction versus temperature can give important information about the thermal behaviour of the material, using some characteristic parameters described here below.

In this paper, the study of the liquid fraction curve has been performed along two axes. First, the liquid fraction versus temperature has been obtained at equilibrium for several alloys theoretically using a thermodynamic prediction package. Then, the same curves have been experimentally obtained on six different alloys at low heating rate by Differential Thermal Analysis (DTA). The results have been analysed to observe the influence of alloying elements and of the heating rate.

In this paper, a high alloyed chromium steel with variations in the composition of manganese and silicon has been studied.

\section{CHARACTERIZING PARAMETERS FOR LIQUID FRACTION CURVES}

Some parameters have already been given by Kazakov [1] for the liquid fraction versus temperature curve. However, they have been adapted for the present case. The parameters are represented on the figure 1 and are:

- The solidus and liquidus temperature, $\mathrm{T}_{\mathrm{S}}$ and $\mathrm{T}_{\mathrm{L}}$

- The temperature at $50 \%$ liquid, $\mathrm{T}_{50 \%}$.

- The melting interval, $T_{L}-T_{S}$

- The semi-melting interval, $\mathrm{T}_{50 \%}-\mathrm{T}_{\mathrm{S}}$, interesting because containing the thixoforming window

- The slope at 10 and 50\% liquid, $\left(\mathrm{d}_{\mathrm{f}} / \mathrm{d}_{\mathrm{T}}\right)_{10 \%}$ (not shown on figure 1$)$ and $\left(\mathrm{d}_{\mathrm{f}} / \mathrm{d}_{\mathrm{T}}\right)_{50 \%}$ 


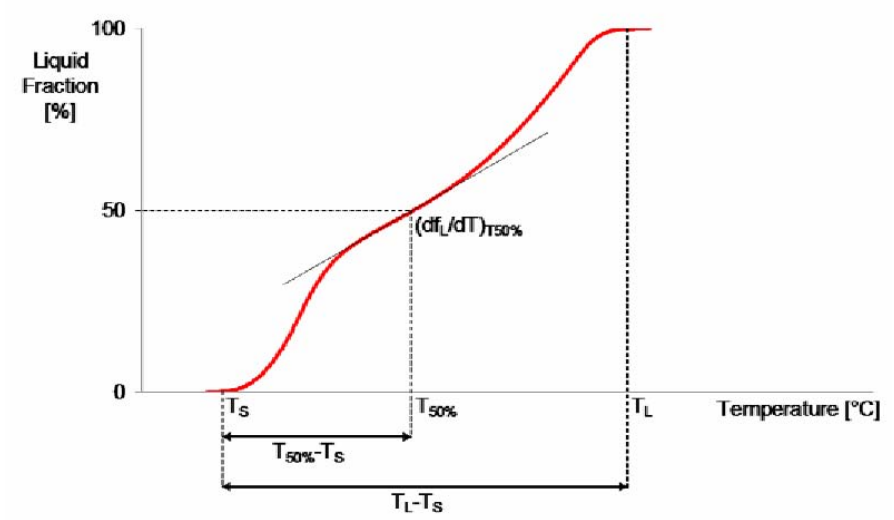

Fig.1. Liquid fraction curve parameters

\section{DESCRIPTION OF THE MATERIAL}

The basis composition of the chromium steel studied is $1.8-1.9 \% \mathrm{C}$ and $12-14 \% \mathrm{Cr}$. Manganese and Silicon have been chosen as varying alloying elements in this study, due to their mechanical and thermal influences on the alloys. The choice of the percentage has been taken, for the lower value, from the initial alloy and, for the higher, from the breaking down of the properties due to this alloying element.

Six chemical compositions have then been analysed (table 1), with Manganese and Silicon variations.

Table 1. Mn and Si weight percentage in the six alloys studied

\begin{tabular}{lll}
\hline Margin & $\% \mathrm{Si}$ & $\% \mathrm{Mn}$ \\
\hline Alloy 1 & 0.48 & 0.99 \\
Alloy 2 & 1.54 & 1.0 \\
Alloy 3 & 3.0 & 1.01 \\
Alloy 4 & 0.6 & 1.53 \\
Alloy 5 & 1.68 & 1.52 \\
Alloy 6 & 3.26 & 1.47 \\
\hline
\end{tabular}

\subsection{Influence of Manganese and Silicon on the mechanical properties}

Manganese increases the hardness, the wear resistance and the elastic limit. It favours hot treatment of steels. It also forms carbides and sulphides $(\mathrm{MnS})$ that prevent the formation of $\mathrm{FeS}$, which is very detrimental to the mechanical properties.

Silicon increases the hardness, the wear resistance, the elastic limit and the oxidation resistance.

These influences are positive for the use of the alloy in mechanical applications.

\subsection{Influence of Manganese and Silicon on the thermal properties}

Manganese stabilises the austenitic phase. It decreases the pearlitic transformation and the liquidus temperature.

Silicon stabilises the ferritic phase. It also decreases the liquidus temperature.

These influences are positive in the case of thixoforming.

\section{EQUILIBRIUM STUDY}

\subsection{Thermodynamical studies}

A thermodynamic package for the predicting equilibrium diagrams, phase compositions or phase fractions for all chemical compositions has been used (MTData). It so permits a decrease in the number of experimental tests, expensive in time and in material.

\subsection{Liquid fraction curves}

First at all, MTData has been used to obtain the behaviour of the alloy across the entire interval of temperature, between room temperature and melting state (figure 2). It appears that at lower temperature, equilibrium microstructure is composed of pearlite, ferrite associated with cementite, and carbides of two types, $\mathrm{M}_{7} \mathrm{C}_{3}$ and $\mathrm{M}_{3} \mathrm{C}_{2}$. This last carbide doesn't exist in real alloys; it could only appear at equilibrium state. Austenitic phase appears around $760^{\circ} \mathrm{C}$ and pearlite disappears just about $780^{\circ} \mathrm{C}$. Dissolution of the carbides ends at $1260^{\circ} \mathrm{C}$, which means approximately at the solidus temperature. Liquidus temperature, which, in this case, signifies the complete melting of austenite, reads $1370^{\circ} \mathrm{C}$.

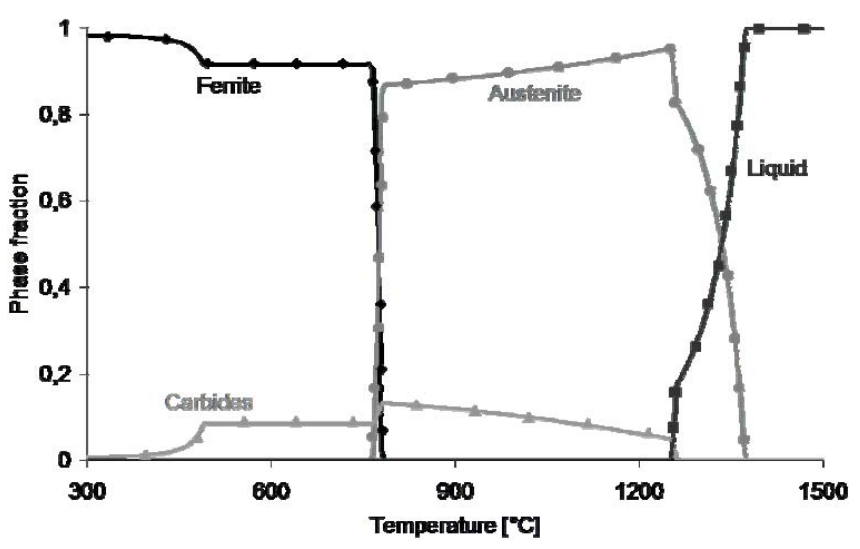

Fig.2. Evolution of the phases at equilibrium, MTData 
The most interesting parameter for thixoforming is nevertheless the melting interval. The influence of silicon and manganese has been studied more precisely in this domain of temperature. The influence of manganese is seen on figure 3; table 2 shows the results obtained for the solidus temperature, and table 3 , the melting interval obtained for all the alloys studied.

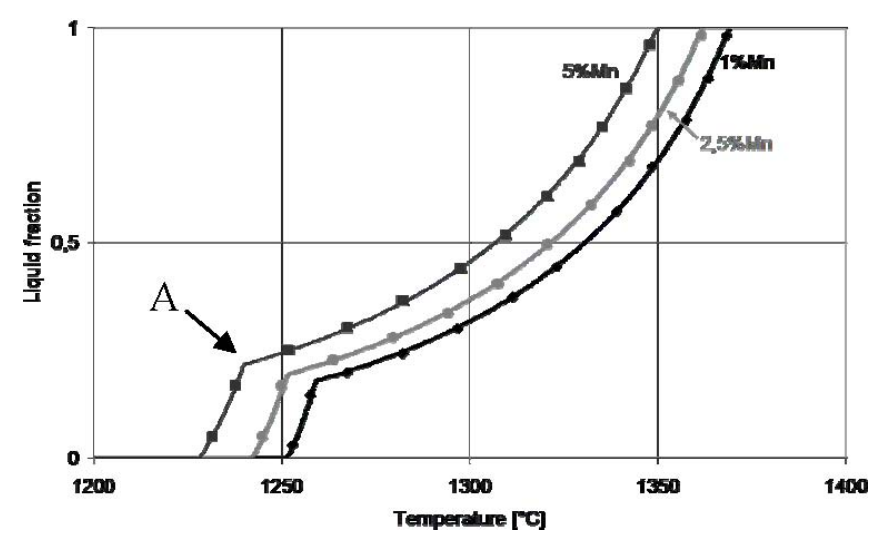

Fig.3. Liquid fraction evolution: influence of manganese

Table 2. Solidus temperature $\left[{ }^{\circ} \mathrm{C}\right]$, function of $\% \mathrm{Mn}$ and $\% \mathrm{Si}$

\begin{tabular}{llllll}
\hline & & $0.5 \% \mathrm{Si}$ & $1.5 \% \mathrm{Si}$ & $3 \% \mathrm{Si}$ & $5 \% \mathrm{Si}$ \\
\hline 1 & $\% \mathrm{Mn}$ & 1251 & 1245 & 1230 & - \\
$1.5 \% \mathrm{Mn}$ & 1248 & 1242 & 1239 & - \\
3 & $\% \mathrm{Mn}$ & 1242 & 1239 & 1227 & 1194 \\
5 & $\% \mathrm{Mn}$ & 1228 & 1229 & 1223 & 1194 \\
\hline
\end{tabular}

Table 3. Melting interval $\left[{ }^{\circ} \mathrm{C}\right]$, function of $\% \mathrm{Mn}$ and $\% \mathrm{Si}$

\begin{tabular}{|c|c|c|c|c|}
\hline & $0.5 \% \mathrm{Si}$ & $1.5 \% \mathrm{Si}$ & $3 \% \mathrm{Si}$ & $5 \% \mathrm{Si}$ \\
\hline $1 \% \mathrm{Mn}$ & 118 & 97 & 70 & - \\
\hline $1.5 \% \mathrm{Mn}$ & 116 & 94 & 64 & - \\
\hline $3 \% \mathrm{Mn}$ & 120 & 95 & 66 & 42 \\
\hline $5 \% \mathrm{Mn}$ & 122 & 93 & 58 & 32 \\
\hline
\end{tabular}

Thanks to this software, more than 6 experimental alloys have been studied, allowing a better analysis of the influence of the elements.

It has been pointed out that Silicon and Manganese lead to a decrease in solidus temperature. However it seems that the influence of Silicon depends also on the amount of Manganese and vice-versa. The same influence is observed on the liquidus temperature.

It appears also that increasing Silicon and Manganese content leads to a narrowing of the melting interval. However, Manganese seems to enlarge it slightly when the amount of Silicon is under $0.9 \%$.

The measurement of the slope is also very important to know the sensitivity of the variation of liquid fraction with temperature. Nevertheless, no clear influence of the elements has been observed.
One other important parameter for thixoforming is the break in the slope, named $\mathrm{A}$ in figure 3 , which is, in this case, situated in the process window (20 $40 \%$ liquid fraction).

Effectively, at low liquid fraction, the slope is steeper. It has been observed that the break in the slope is less marked when there are more alloying elements, but that slope break occurs at lower liquid fraction when the amount of Silicon and Manganese is lower.

All these measurements correspond to equilibrium conditions. To approach progressively the industrial conditions, it is important to observe the same curves at low and then at high heating rates (with inductive heating). In this paper, the low heating rates have been analysed by Differential Thermal Analysis.

\section{DTA RESULTS}

\subsection{Differential Thermal Analysis}

Differential Thermal Analysis - DTA - leads to a DTA-Signal that can be integrated between the solidus and the liquidus temperature to obtain the curve of liquid fraction versus temperature, as it can be seen on figure 4 . These experiments are limited to low heating rates, but offer the possibility to approximate to the equilibrium state.

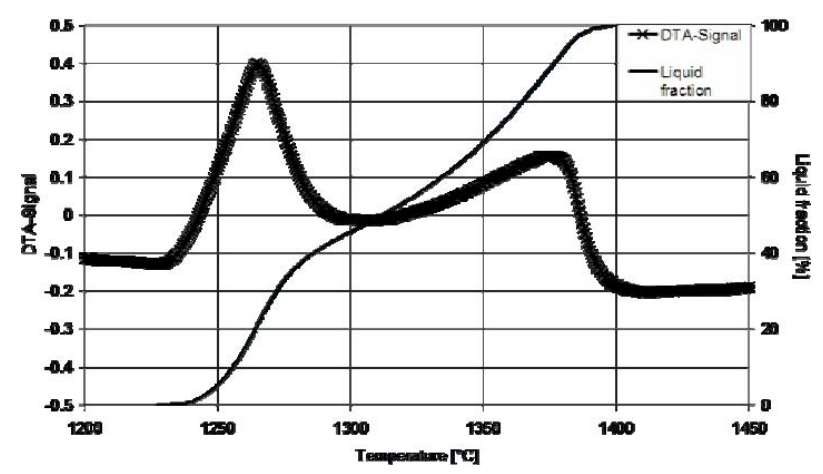

Fig.4. Integration of the DTA-Signal to obtain liquid fraction

Before speaking exactly of the influences of Manganese, Silicon and of the heating rate, it is important to note that the curves obtained with low heating rates correspond to the ones obtained at equilibrium with MTData. DTA-Signal (figure 5) shows a first peak which corresponds to the austenitic transformation. Then, the melting interval is composed of two peaks, the first one, due to the carbide dissolution and the second one, corresponding to the melting of the austenite. 


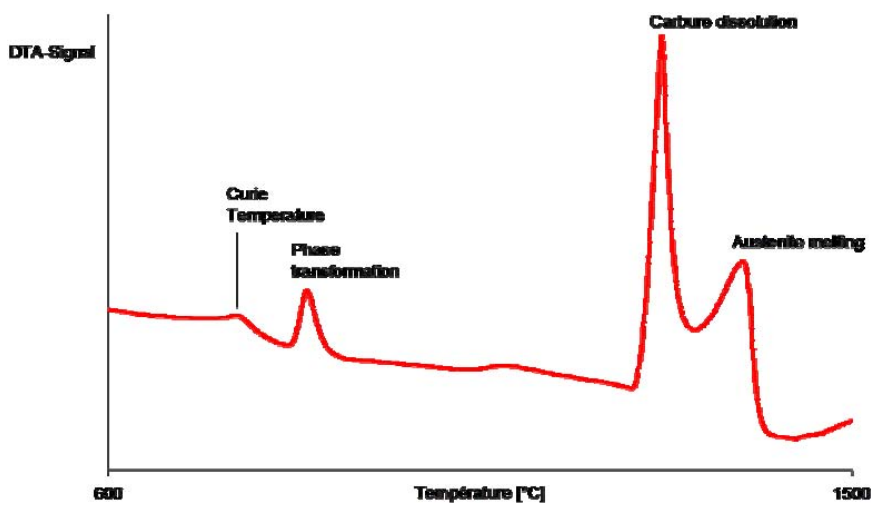

Fig.5. DTA-Signal of the alloy $1(0.5 \% \mathrm{Si}, 1.0 \% \mathrm{Mn})$

\subsection{Liquid fraction curves}

By increasing the Silicon content in the alloy, the solidus and liquidus temperatures decrease, which can be very positive for thixoforming. However, it also causes a narrowing of the melting and semimelting interval.

The effect of Manganese is similar but not marked in the range content studied (1.0 and 1.5\%, table 1). [2] The influence of the heating rate has also been observed. Table 4 gives the results obtained for a heating rate of 2,10 and $15^{\circ} \mathrm{C} / \mathrm{min}$ for the alloy 1 $(0.5 \% \mathrm{Si}, 1 \% \mathrm{Mn})$.

Table 4. Measurements of parameters on the liquid fraction curve for alloy $1(0.5 \% \mathrm{Si}, 1 \% \mathrm{Mn})$ at different heating rates

\begin{tabular}{|c|c|c|c|c|}
\hline & $\mathrm{T}_{\mathrm{S}}\left[{ }^{\circ} \mathrm{C}\right]$ & $\mathrm{T}_{\mathrm{L}}\left[{ }^{\circ} \mathrm{C}\right]$ & $\mathrm{T}_{\mathrm{L}}-\mathrm{T}_{\mathrm{S}}\left[{ }^{\circ} \mathrm{C}\right]$ & $\left(\mathrm{d}_{\mathrm{f}} / \mathrm{d}_{\mathrm{T}}\right)_{10 \%}$ \\
\hline $2{ }^{\circ} \mathrm{C} / \mathrm{min}$ & 1235 & 1390 & 155 & 1.727 \\
\hline $10^{\circ} \mathrm{C} / \mathrm{min}$ & 1231 & 1402 & 171 & 1.223 \\
\hline $15^{\circ} \mathrm{C} / \mathrm{min}$ & 1229 & 1405 & 176 & 0.973 \\
\hline
\end{tabular}

It appears that an increase of the heating rate leads to a slight decrease of solidus temperature and enhancement of liquidus temperature, which automatically causes an enlargement of the melting interval. The slope at $50 \%$ liquid seems to be a little steeper, and at $10 \%$ becomes lower. Globally, the slope change tends to become less marked with a higher heating rate.

\section{CONCLUSIONS}

The characterization of the melting interval and of all the thermal parameters in semi-solid state is essential for the study of thixoforming. Effectively, the thermal parameters have to be determined to allow experiments at the high heating rate needed in industrial behaviour (inductive heating) and to perform thermal and mechanical modelling. In the present study, the melting interval and the solidus temperature have been analysed in two states. The first one was at equilibrium using thermodynamic software, MTData. The second one was at low heating rates, with DTA. It has been pointed out that Manganese and Silicon decrease the solidus temperature, which is good for the thixoforming window. However, it has been shown in both states that Silicon and Manganese have to be kept at medium level. Effectively, increasing the alloying elements content leads to a decrease of the melting interval. Finally, increasing the heating rate seems to have a good influence on the behaviour of the studied alloys in semi-solid state.

Based on this study, the next step is to make experiments at a high heating rate, with inductive heating, to approach industrial behaviour.

\section{REFERENCES}

1. A.A. Kazakov, Alloy Compositions for Semisolid Forming, Advanced Material and Processes (2000) 3134.

2. C. Fraipont, J. Lecomte-Beckers, Determination of the Influence of the Thixoformability of a Chromium Steel, $10^{\text {th }}$ Esaform Conference on Material Forming (April 2007), 1113-1117, Zaragoza, Spain

3. Z. Azpilgain, I. Hurtado, R.Ortubay, I. Landa and J. Atxa, Semisolid Forging of 7000 Series Aluminum Alloys, Solid State Phenomena (2006) 758-761

4. D. Liu, H.V. Atkinson and H. Jones, Thermodynamic prediction of thixoformability in alloys based on the Al$\mathrm{Si}-\mathrm{Cu}$ and $\mathrm{Al}-\mathrm{Si}-\mathrm{Cu}-\mathrm{Mg}$ systems, Acta Materialia, Vol 53, Issue 14 (2005) 3807-3819

5. RH Davies, AT Dinsdale, JA Gisby, JAJ Robinson and SM Martin, MTDATA - thermodynamic and phase equilibrium software from the national physical laboratory, Calphad, Vol 26, Issue 2 (2002) 229-271 